\title{
IUGS Publication Policy
}

The International Union of Geological Sciences (IUGS) expects that most scientific activities funded by the Union will result in some form of publication. Publication arrangements should generally seek the widest possible visibility and distribution of IUGS results to interested scientific and lay audiences.

IUGS New Publication Series. The IUGS New Publication Series (NPS) provides publication outlet for the scientific work of the Union and ensures that results are available to others in a form that is functional yet inexpensive. The Series gives particular encouragement to works that may be produced quickly and at low cost, and hence made more readily available to readers in developing countries. The NPS is governed by the following policy guidelines.

1. The NPS is administered by the IUGS Advisory Board for Publications (ABP) in consultation with the IUGS Executive Committee. The ABP Chairman, or a delegate, acts as Editor-in-Chief for the Series.

2. Prospective contributors to the Series must discuss publication matters fully with the Editor-in-Chief when planning a manuscript, well before proceeding to produce camera-ready copy for publication. Manuscripts are submitted to the Editor-in-Chief, who determines whether it meets appropriate scientific standards and conforms with current IUGS publication policy.

3. The Editor-in-Chief is responsible for assigning NPS numbers and, where appropriate, ISBN numbers to each publication in the Series. The name and logo of the Union and the assigned publication number should appear in a conspicuous place on the cover and/or title page of each publication in the Series. A brief standard deseription of the Union should be printed on the reverse side of the title page, or in some other prominent place, as follows: "The International Union of Geological Sciences is a non-governmental scientific organization that promotes the study of geological problems, especially those of worldwide significance, and facilitates international and interdisciplinary cooperation in the geosciences."

4. Ilustration, references, abbreviations, eitations, etc. should conform to international standards. English is encouraged as the language of publication. Authors and editors are responsible for the technical content of the material.

5. The Editor-in-Chief may assist the author or editor in arranging production and printing of the publication at the lowest cost consistent with acceptable standards. The Union may be able to take on the task of printing, but not without prior consultation with and approval from the Editor-in-Chief.

6. Financial arrangements (production and printing costs, sales prices, royalties, discounts...) and the number of complimentary copies that will be provided to authors and editors are determined in consultation with the Editor-in-Chief, who in turn will seek approval from the IUGS Treasurer.

7. IUGS will retain copyright on all NPS volumes.

8. IUGS will assist in the promotion and distribution of NPS publications. Distribution centers are designated by the Editor-in-Chief in consultation with the SecretaryGeneral. NPS publications must be made available from IUGS distribution centers.
Outside Publication. For a variety of reasons, it may be more appropriate and advantageous to the Union and to authors as well for Union-funded work to be published outside the NPS. These outlets typically include scientific journals, monographs, maps and charts published by scientific and professional organizations, and by commercial (for-profit) publishers. The following guidelines apply to publication of IUGS-sponsored work outside the NPS.

1. All publications, including but not limited to articles, monographs, maps and charts, must carry a clear statement, prominently displayed, acknowledging the IUGS contribution. In most cases, the statement will take the following form:

"This (project, symposium, workshop, etc.) was sponsored (co-sponsored, supported etc.) by the International Union of Geological Sciences (IUGS)."

2. Where appropriate, monographs, maps, charts and journals should carry the name and logo of the Union, in addition to the above statement. In monographs, the logo and statement of sponsorship will normally be placed on the cover, title page or other front matter. On maps and charts, design considerations require flexibility in the placement of the logo and statement of sponsorship, but, nevertheless, the message must be clear.

3. The Union expects that, whenever possible, other organizations publishing the results of IUGS-sponsored work will pay to the Union a royalty on the sale of such publications.

4. Where appropriate, the Union will negotiate to retain copyright or an equitable share of copyright to any IUGS-sponsored work published by other organizations.

5. The Union expects to assist in promoting the distribution of IUGS-related or sponsored publications, whether published by the IUGS or others, through announcements in Episodes, direct-mail flyers, and at IUGS displays at conferences and meetings.

6. Any publishing arrangement with outside publishers should provide the IUGS with a reasonable number of complimentary copies for promotion, display, review, and other official uses. In addition and when feasible, the arrangement negotiated should consider free distribution of a reasonable number of copies of the product to appropriate libraries, designated by IUGS, in developing countries.

Responsibilities. The IUGS Secretary-General is responsible for informing all IUGS bodies of the current publication policy and for encouraging compliance. The Chairman of the ABP may, on request, assist in this task. The IUGS Executive Committee, through the Secretary General, will make it explicit and clear to each recipient of support for scientific endeavors that if Union funds are awarded in anticipation of published results, a condition of funding is that the recipient will comply with the Union publication policy.

The Secretary General, in consultation with the Treasurer and the Chairman of the Advisory Board for Publications, is responsible for negotiating royalty arrangements with outside publishers, and for approving publication and royalty arrangements made by others on behalf of the Union. 